\title{
Streptomyces speibonae sp. nov., a novel streptomycete with blue substrate mycelium isolated from South African soil
}

Correspondence
Paul R. Meyers
pmeyers@science.uct.ac.za

\author{
Paul R. Meyers, Donovan S. Porter, Clifford Omorogie, J. Motsamai Pule \\ and Thembelani Kwetane
}

\begin{abstract}
Department of Molecular and Cell Biology, University of Cape Town, Private Bag 1, Rondebosch, 7701 Cape Town, South Africa
\end{abstract}

\begin{abstract}
An actinomycete with blue substrate mycelium was isolated from a soil sample in Cape Town, South Africa, and designated strain $\mathrm{PK}-\mathrm{Blue}^{\top}$. The colour of the substrate mycelium was not sensitive to changes in $\mathrm{pH}$. The organism produced hairy spores in Spirales-type spore chains. Chemical taxonomy indicated that it belonged to the genus Streptomyces. Strain PK-Blue ${ }^{\top}$ produced no diffusible pigments other than melanin, grew at $45^{\circ} \mathrm{C}$, did not degrade adenine and exhibited no antibacterial activity against Enterococcus faecium, Escherichia coli or Pseudomonas aeruginosa. Analysis of its 16S rRNA gene sequence and the results of

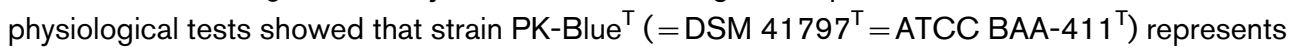
the type strain of a novel species of Streptomyces, for which the name Streptomyces speibonae sp. nov. is proposed.
\end{abstract}

Actinomycetes are widely distributed in terrestrial environments, from which they are easy to isolate. This fact, plus their broad metabolic capabilities and their ability to produce pigments and antibiotics, makes them fascinating and suitable subjects for undergraduate microbiology projects.

Streptomycetes may represent a considerable proportion of the actinomycete communities in soils (Elander, 1987). Despite the fact that streptomycetes have been studied extensively for many decades and many species have been described, from time to time, a novel streptomycete is isolated.

Strain PK-Blue ${ }^{\mathrm{T}}$ was isolated by J. M. Pule and T. Kwetane on the Upper Campus of the University of Cape Town (South Africa) in August 2000, as part of their 3rd year BSc project on actinomycetes.

Morphological and physiological characteristics were determined as recommended by Williams et al. (1989), with the exception that antibiotic resistance was determined by incorporation of the antibiotics into Bennett's medium agar plates (Atlas, 1993) at the concentrations recommended instead of using antibiotic-impregnated filter discs. Non-standard antibiotics were tested at the following

Abbreviations: DAP, diaminopimelic acid; ISP, International Streptomyces Project.

The GenBank accession number for the 16S rRNA gene sequence of Streptomyces speibonae DSM $41797^{\top}\left(=\right.$ ATCC BAA $\left.-411^{\top}\right)$ is AF452714. concentrations: capreomycin $\left(20 \mu \mathrm{g} \mathrm{ml}^{-1}\right)$, cefotaxime $\left(100 \mu \mathrm{g} \mathrm{ml}^{-1}\right)$, D-cycloserine $\left(50 \mu \mathrm{g} \mathrm{ml}^{-1}\right)$, kanamycin $\left(10 \mu \mathrm{g} \mathrm{ml}^{-1}\right)$ and viomycin $\left(8 \mu \mathrm{g} \mathrm{ml}^{-1}\right)$. Antimicrobial activity against Enterococcus faecium, Escherichia coli and Pseudomonas aeruginosa was determined using 5-day-old colonies of strain PK-Blue ${ }^{\mathrm{T}}$ grown on nutrient agar (Williams et al., 1989).

International Streptomyces Project (ISP) media were prepared according to the methods of Shirling \& Gottlieb (1966). Tests for physiological characteristics were carried out at $28{ }^{\circ} \mathrm{C}$ (unless otherwise indicated) and results were read after the recommended incubation periods. All carbon sources for carbon-utilization tests were filter-sterilized. meso-Erythritol, glycerol, maltose, methyl $\alpha$-D-glucoside, $\mathrm{D}(-)$-ribose and $\mathrm{L}(-)$-sorbose were tested as sole carbon sources at concentrations of $1 \%(\mathrm{w} / \mathrm{v})$. Sodium benzoate, sodium butyrate, sodium formate, sodium DL-malate, sodium maleate, sodium oxalate, sodium salicylate, sodium succinate and sodium $\mathrm{L}(+)$-tartrate were tested as sole carbon sources at $0 \cdot 1 \%(\mathrm{w} / \mathrm{v})$. DL-Citrulline, DL-ornithine and 4-amino- $n$-butyric acid were tested as sole nitrogen sources at $0 \cdot 1 \%(\mathrm{w} / \mathrm{v})$.

Determination of the isomer of diaminopimelic acid (DAP) and the whole-cell sugar pattern were carried out as described by Hasegawa et al. (1983) with the exception that dried cells were used instead of colonies from agar plates. Fatty acid methyl esters were prepared by the trimethylsulphonium hydroxide method (Butte, 1983). The base composition of genomic DNA of strain PK-Blue ${ }^{\mathrm{T}}$ was 
determined in $0 \cdot 1 \times$ SSC by the method of Mandel \& Marmur (1968).

A 16S rRNA gene sequence of strain PK-Blue ${ }^{\mathrm{T}}$ was amplified by PCR using universal bacterial $16 \mathrm{~S}$ rDNA primers (forward primer adapted from primer fD1 of Weisburg et al., 1991; reverse primer adapted from primer p1525r of Chun \& Goodfellow, 1995). The 16S rDNA was sequenced using an ALFexpress DNA automated sequencer (Applied Biosystems) and an Amersham Pharmacia Biotech Cy5 Thermo Sequenase dye terminator kit.

Strain PK-Blue ${ }^{\mathrm{T}}$ was Gram-positive by Gram stain, did not grow under anaerobic conditions and gave a positive reaction in the catalase test. Light microscopy showed a branched mycelium without verticils. Scanning electron microscopy revealed Spirales-type spore chains with hairy spore sheaths (Fig. 1). Chemotaxonomic tests showed that the cell wall contained LL-DAP, indicating that it has cell-wall type I; no diagnostic sugars were detected in hydrolysates of whole cells. Fatty acid analysis showed that strain PK-Blue ${ }^{\mathrm{T}}$ contained a high proportion of saturated
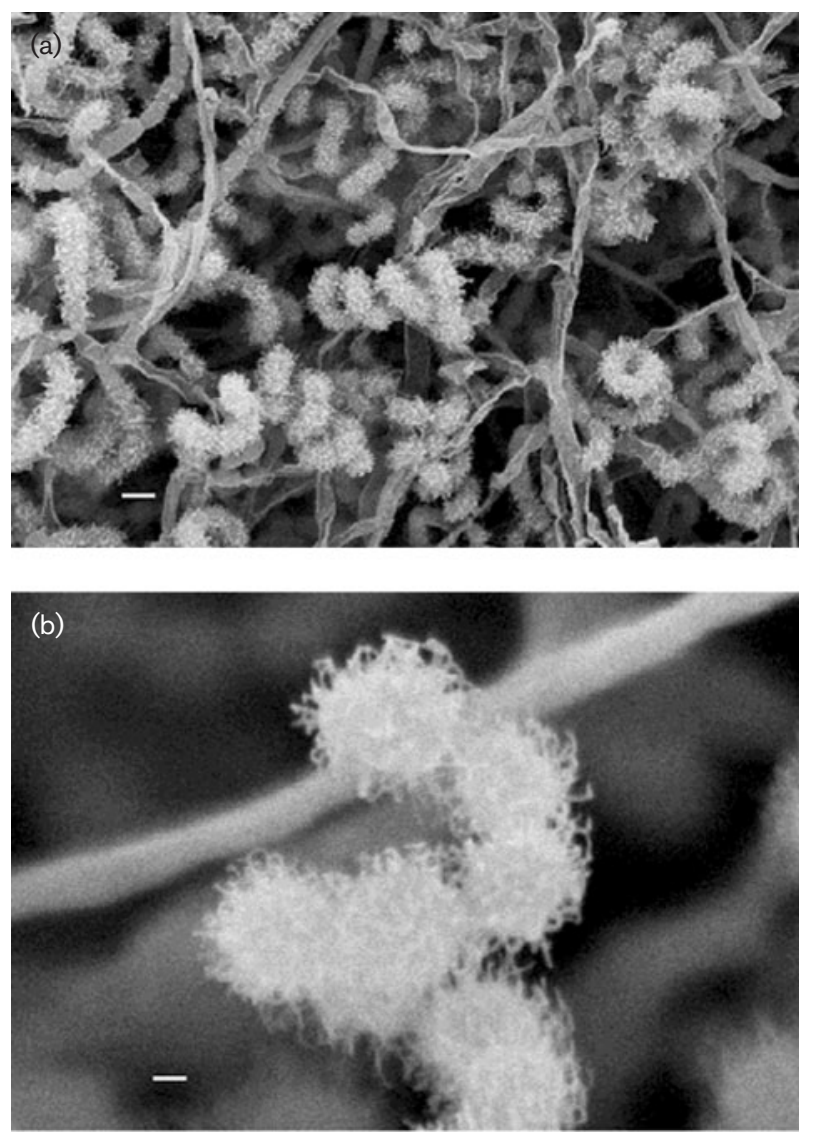

Fig. 1. Scanning electron micrographs of strain $\mathrm{PK}-\mathrm{Blue}^{\top}$ grown on inorganic salts-starch agar (ISP medium no. 4) at $28-30{ }^{\circ} \mathrm{C}$ for 14 days. Spirales-type spore chains with hairy spore sheaths are clearly evident. Bars, $1 \mu \mathrm{m}$ (a) and $250 \mathrm{~nm}$ (b). straight-chain and iso- and anteiso-branched fatty acids: iso-15:0 (12.0\%), iso-16:0 (35.9\%), $16: 0(14.9 \%)$ and anteiso-17:0 $(9 \cdot 4 \%)$. The $\mathrm{G}+\mathrm{C}$ content of the genomic DNA was $73 \cdot 4 \mathrm{~mol} \%$.

A 1490-bp 16S rRNA gene sequence was determined for strain PK-Blue ${ }^{\mathrm{T}}$. A standard nucleotide-nucleotide BLAST search (Altschul et al., 1997) against the GenBank database using this sequence showed that it was most similar to the $16 \mathrm{~S}$ rDNA sequences of 'Nocardioides thermolilacinus' strains IFO 14336 and IFO 14335 (both $98 \%$ similar over $1471 \mathrm{nt}$ ) and many species of Streptomyces. Although it was surprising that the highest similarity of the PK-Blue ${ }^{T} 16 \mathrm{~S}$ rDNA was to ' $N$. thermolilacinus' (strain PK-Blue ${ }^{\mathrm{T}}$ does not have a Nocardioides-type life cycle), these organisms are considered to have been misidentified and are believed to be streptomycetes (Prauser, 1989).

A phylogenetic tree of Streptomyces 16S rDNA sequences was constructed by the neighbour-joining method of Saitou \& Nei (1987) using CLUSTAL W (version 1.81) and MEGA (version 2.1; Kumar et al., 2001) (Fig. 2).

The morphological and physiological characteristics of strain PK-Blue ${ }^{\mathrm{T}}$, as well as its cell-wall type, its whole-cell sugar pattern, its fatty acid profile and the sequence of its $16 \mathrm{~S}$ rRNA gene, are consistent with the characteristics of members of the genus Streptomyces. Strain PK-Blue ${ }^{\mathrm{T}}$ produced a blue substrate mycelium and a grey spore mass composed of hairy spores in Spirales-type spore chains. It produced melanin, but did not produce any other diffusible pigments.

Strain PK-Blue ${ }^{\mathrm{T}}$ differs from other streptomycetes that produce a blue substrate mycelium in several respects. Some strains of Streptomyces griseoflavus produce a blue substrate mycelium (Williams et al., 1989), but this species differs from PK-Blue ${ }^{\mathrm{T}}$ in producing Retinaculiaperti spore chains and a green or yellow spore mass and by its ability to hydrolyse pectin and degrade adenine. Most strains of S. griseoflavus do not produce melanin. S. griseoflavus does not degrade xanthine, is sensitive to vancomycin and does not grow at $45^{\circ} \mathrm{C}$ or in the presence of $10 \% \mathrm{NaCl}$. PK-Blue ${ }^{\mathrm{T}}$ grows on L-valine as a sole nitrogen source and on sodium malonate as a sole carbon source. S. griseoflavus does not use either of these.

There are no full-length or almost-complete 16S rDNA sequences for $S$. griseoflavus (or any of its subjective synonyms: Streptomyces cyanoalbus, Streptomyces hirsutus, Streptomyces pilosus, Streptomyces prasinopilosus and Streptomyces prasinus) in the GenBank database. However, 119-121 bp sequences, from the variable $\alpha$ region of the $16 \mathrm{~S}$ rRNA molecule, have been determined for each of these species (Kataoka et al., 1997). These single sequences correspond to nucleotide positions 158-277 of the Streptomyces ambofaciens $16 \mathrm{~S}$ rRNA sequence of the $\mathrm{rrnD}$ rRNA gene cluster (Pernodet et al., 1989). The similarity of these sequences to the PK-Blue ${ }^{T} 16 \mathrm{~S}$ rDNA sequence was 


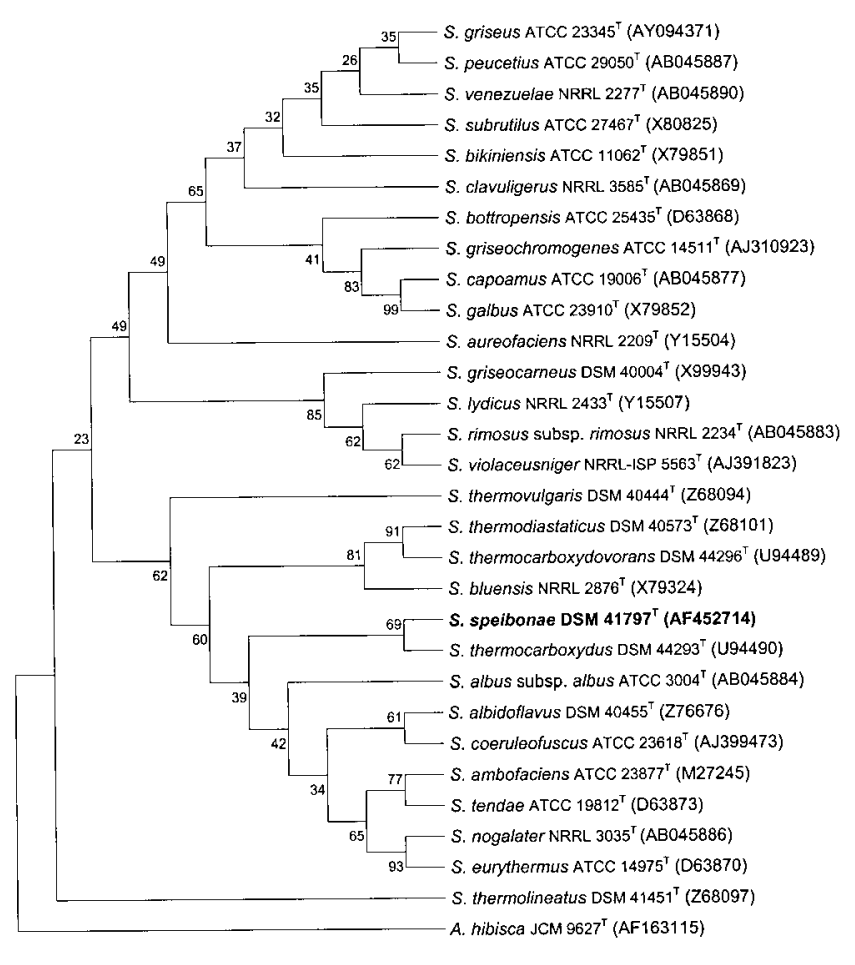

Fig. 2. Unrooted phylogenetic tree constructed from almostcomplete Streptomyces 16S rRNA gene sequences, showing the relationship between Streptomyces speibonae sp. nov. and streptomycetes belonging to the major, minor and singlemember clusters defined by Williams et al. (1983). The sequence of the 16S rRNA gene of Actinomadura hibisca JCM $9627^{\top}$ was used as an outgroup. All sequences were edited to produce the longest sequence region common to all sequences (1440 bp). GenBank sequence accession numbers are given in parentheses. The tree was generated using the neighbourjoining method (CLUSTAL W version 1.81 and MEGA version 2.1) and includes bootstrap percentages based on an analysis of 1000 resampled datasets.

determined by pairwise alignment using the DNAMAN software (Lynnon BioSoft; version 4.13). The range of similarity is $83.2 \%$ (S. prasinopilosus JCM $4404^{\mathrm{T}}$; accession no. D44119) to $96 \cdot 7 \%$ (S. griseoflavus JCM $4479^{\mathrm{T}}$; D44174). These differences eliminate the possibility that $\mathrm{PK}-\mathrm{Blue}^{\mathrm{T}}$ is a member of the S. griseoflavus species group.

Streptomyces anthocyanicus, Streptomyces caeruleus, Streptomyces tricolor and Streptomyces violaceoruber produce blue substrate mycelia (Williams et al., 1989), but differ from PK-Blue ${ }^{T}$ in producing smooth spores and in the production of diffusible pigments. Strain $\mathrm{PK}-\mathrm{Blue}^{\mathrm{T}}$ produces Spirales-type spore chains, whereas S. anthocyanicus has Retinaculiaperti-type spore chains and S. caeruleus has Rectiflexibiles-type spore chains. S. anthocyanicus, $S$. caeruleus and $S$. violaceoruber do not produce melanin. Strain PK-Blue ${ }^{\mathrm{T}}$ uses, as sole carbon sources, $\mathrm{L}(+)$ arabinose, $\mathrm{L}(+)$-rhamnose, $\mathrm{D}(+)$-xylose $(S$. caeruleus does not use any of these) and D-mannitol (not used by
S. anthocyanicus). Strain PK-Blue ${ }^{\mathrm{T}}$ does not use salicin ( $S$. violaceoruber is able to use this glucoside as a sole carbon source).

The single available $121 \mathrm{bp}$ sequences for S. anthocyanicus JCM $5058^{\mathrm{T}}$, S. tricolor JCM $5065^{\mathrm{T}}$ and S. violaceoruber JCM $4423^{\mathrm{T}}$, from the variable $\alpha$ region (Kataoka et al., 1997), all show $89 \cdot 3 \%$ similarity to the PK-Blue ${ }^{\mathrm{T}} 16 \mathrm{~S}$ rDNA sequence by pairwise alignment (accession nos D44427, D44434 and D44135, respectively). A 451 bp $16 \mathrm{~S}$ rDNA sequence of S. violaceoruber (AF434717) shows only $35 \cdot 8 \%$ similarity to the PK-Blue ${ }^{\mathrm{T}} 16 \mathrm{~S}$ rDNA sequence by pairwise alignment. These differences support the other evidence that strain PK-Blue $\mathrm{T}^{\mathrm{T}}$ is not a strain of S. anthocyanicus, S. caeruleus, S. tricolor or S. violaceoruber.

Strain PK-Blue ${ }^{\mathrm{T}}$ also differs from other streptomycetes that produce hairy spores. Streptomyces acrimycini produces a green spore mass and no melanin (Williams et al., 1989). Streptomyces bambergiensis has Retinaculiaperti-type spore chains and a green spore mass. It produces a $\mathrm{pH}$-sensitive red-orange substrate mycelium and $\mathrm{pH}$-sensitive redorange diffusible pigments, but no melanin. This species is also sensitive to lincomycin $\left(100 \mu \mathrm{g} \mathrm{ml}^{-1}\right)$ (Williams et al., 1989).

Streptomyces capillispiralis differs from strain PK-Blue ${ }^{\mathrm{T}}$ in producing a light brownish-grey spore mass and yellowbrown to brownish-black substrate mycelium. A brown diffusible pigment may be produced, but melanin is not produced. This species produces urease, but does not degrade starch or reduce nitrate (Williams et al., 1989).

Streptomyces chromofuscus produces a yellow-brown substrate mycelium and is sensitive to oleandomycin $\left(100 \mu \mathrm{g} \mathrm{ml}^{-1}\right)$. Most strains produce smooth spores. Streptomyces flaveolus and Streptomyces pactum produce yellow-brown substrate mycelia and yellow-brown diffusible pigments, but no melanin. S. pactum is also unable to use $\mathrm{D}(+)$-xylose as a sole carbon source (Williams et al., 1989).

Streptomyces finlayi differs from PK-Blue ${ }^{\mathrm{T}}$ in producing Rectiflexibiles-type spore chains, a green substrate mycelium and no melanin. This species is sensitive to lincomycin $\left(100 \mu \mathrm{g} \mathrm{ml}^{-1}\right)$ (Williams et al., 1989).

Streptomyces geysiriensis differs from $\mathrm{PK}-\mathrm{Blue}^{\mathrm{T}}$ in not producing melanin. Streptomyces glaucescens produces a blue spore mass, a red-orange substrate mycelium and redorange diffusible pigments. This species also lacks proteolytic activity (Williams et al., 1989).

Streptomyces griseostramineus produces a green spore mass and greyish-yellow or greyish-yellow-green substrate mycelium. Streptomyces prasinosporus produces a green spore mass, yellow-brown substrate mycelium and no melanin on tyrosine agar. It is also unable to degrade tyrosine or to use L-arginine as a sole nitrogen source (Williams et al., 1989). 
Streptomyces viridoviolaceus differs from strain $\mathrm{PK}-\mathrm{Blue}^{\mathrm{T}}$ in producing a light brownish-grey to greyish-yellow-brown spore mass, reddish- or yellowish-brown substrate mycelium and orange or red, $\mathrm{pH}$-sensitive diffusible pigments. Melanin pigment is not produced (Williams et al., 1989).

These results support the classification of strain PK-Blue ${ }^{\mathrm{T}}$ as a novel species of Streptomyces, for which we propose the name Streptomyces speibonae sp. nov. Additional data from the phenotypic characterization of the strain are presented below

\section{Description of Streptomyces speibonae sp. nov.}

Streptomyces speibonae (spei.bo'nae. L. n. spes -ei hope; L. adj. bonus good; N.L. masc. adj. speibonae of good hope, to indicate Cape Town, the Cape of Good Hope, South Africa, the geographical location from which the type strain was isolated).

Aerobic, Gram-positive, catalase-positive actinomycete that forms a grey aerial mycelium and a blue substrate mycelium. The colour of the substrate mycelium is not $\mathrm{pH}$ sensitive. Verticils are not present. The mycelium does not fragment. Spirales-type spore chains with hairy spore sheaths are produced. No diffusible pigments are produced on glycerolasparagine agar (ISP medium no. 5) or on any other medium. Melanin pigment is produced on both peptoneyeast extract-iron agar (ISP medium no. 6) and tyrosine agar (ISP medium no. 7). Although growth on inorganic saltsstarch agar (ISP medium no. 4) is initially slow, very good growth with profuse sporulation is observed on this medium after 14 days. Very good growth occurs on yeast extract-malt extract agar (ISP medium no. 2). Good growth is observed on oatmeal agar (ISP medium no. 3) and moderate growth on Czapek solution agar (Atlas, 1993). Growth on glycerol-asparagine agar is poor. The substrate mycelium is blue on yeast extract-malt extract agar and oatmeal agar, but light grey on the Czapek and glycerolasparagine media. The cell wall contains LL-DAP (cell wall type I). The whole-cell sugar pattern contains no diagnostic sugars. No antibiosis is exhibited against Enterococcus faecium (clinical isolate), Escherichia coli ATCC 25922 or Pseudomonas aeruginosa ATCC 27853. Grows in the presence of ( $\mu \mathrm{g} \mathrm{ml}^{-1}$ unless stated otherwise): cefotaxime (100), cephaloridine (100), D-cycloserine (50), lincomycin (100), oleandomycin (100), penicillin $\mathrm{G}\left(10 \mathrm{IU} \mathrm{ml}^{-1}\right)$, phenol $(0 \cdot 1 \%)$, 2-phenylethanol $(0 \cdot 1 \%)$, sodium chloride $(10 \%)$ and vancomycin $(50)$ and at $45^{\circ} \mathrm{C}$ but not at $4{ }^{\circ} \mathrm{C}, \mathrm{pH} 4.3$ or in the presence of sodium azide $(0.01 \%)$, capreomycin (20), gentamicin (100), kanamycin (10), neomycin (50), rifampicin (50), streptomycin (100), tobramycin (50) or viomycin (8). Uses DL- $\alpha$-amino- $n$-butyric acid, 4 -amino- $n$-butyric acid, L-arginine, DL-citrulline, L-cysteine, L-histidine, L-methionine, DL-ornithine, potassium nitrate, L-serine, L-threonine and L-valine as sole nitrogen sources, but not L-hydroxyproline or L-phenylalanine. Uses $\mathrm{L}(+)$-arabinose, $\mathrm{D}(+)$-cellobiose, $\mathrm{D}(-)$-fructose, $\mathrm{D}(+)$-galactose, glycerol, meso-inositol, lactose, maltose, D-mannitol, $\mathrm{D}(+)$-mannose,
$\mathrm{L}(+)$-rhamnose, $\mathrm{D}(-)$-ribose, sodium acetate, sodium butyrate, sodium DL-malate, sodium malonate, sodium propionate, sodium pyruvate, sodium succinate, sucrose (weak growth), trehalose and $\mathrm{D}(+)$-xylose as sole carbon sources but not adonitol, meso-erythritol, inulin, $\mathrm{D}(+)$ melezitose, $\mathrm{D}(+)$-melibiose, methyl $\alpha$-D-glucoside, raffinose, salicin, sodium benzoate, sodium citrate, sodium formate, sodium maleate, sodium oxalate, sodium salicylate, sodium $\mathrm{L}(+)$-tartrate, $\mathrm{L}(-)$-sorbose or xylitol. Tests for nitrate reductase and the production of $\mathrm{H}_{2} \mathrm{~S}$ are positive, but pectin is not hydrolysed. Lipase and lecithinase are produced on egg-yolk agar, but protease activity is not seen on this medium after the recommended 2 days of incubation (there is weak activity after 6 days). Degrades casein, DNA, gelatin, guanine, hypoxanthine, starch (weakly), Tween 80 , L-tyrosine, xanthine and xylan but not adenine, allantoin or urea.

The DNA G + C content of the type strain, strain PK-Blue ${ }^{\mathrm{T}}$ $\left(=\mathrm{DSM} 41797^{\mathrm{T}}=\right.$ ATCC BAA $\left.-411^{\mathrm{T}}\right)$, is $73 \cdot 4 \mathrm{~mol} \%$.

\section{Acknowledgements}

We thank Di James for DNA sequencing, Miranda Waldron of the Electron Microscope Unit for help with scanning electron microscopy, Carlien Pohl, Neil Ravenscroft, Marilize le Roes and Klaus Achleitner for fatty acid methyl ester analysis, Horst Klump for help in determining the DNA base composition and Andrew Cook for help with Streptomyces $16 \mathrm{~S}$ rDNA sequence analysis. P. R. M. is the recipient of research grants from the University Research Committee (University of Cape Town) and the Medical Research Council of South Africa. D. S. P. holds a Marion Beatrice Waddell Bursary from the University of Cape Town.

\section{References}

Altschul, S. F., Madden, T. L., Schäffer, A. A., Zhang, J., Zhang, Z., Miller, W. \& Lipman, D. J. (1997). Gapped BLAST and PSI-BLAST: a new generation of protein database search programs. Nucleic Acids Res 25, 3389-3402.

Atlas, R. M. (1993). Handbook of Microbiological Media. Edited by L. C. Parks. Boca Raton, FL: CRC Press.

Butte, W. (1983). Rapid method for the determination of fatty acid profiles from fats and oils using trimethylsulphonium hydroxide for transesterification. J Chromatogr 261, 142-145.

Chun, J. \& Goodfellow, M. (1995). A phylogenetic analysis of the genus Nocardia with 16S rRNA gene sequences. Int J Syst Bacteriol 45, 240-245.

Elander, R. P. (1987). Microbial screening, selection and strain improvement. In Basic Biotechnology, pp. 217-251. Edited by J. Bu'Lock and B. Kristiansen. London: Academic Press.

Hasegawa, T., Takizawa, M. \& Tanida, S. (1983). A rapid analysis for chemical grouping of aerobic actinomycetes. J Gen Appl Microbiol 29, 319-322.

Kataoka, M., Ueda, K., Kudo, T., Seki, T. \& Yoshida, T. (1997). Application of the variable region in 16S rDNA to create an index for rapid species identification in the genus Streptomyces. FEMS Microbiol Lett 151, 249-255. 
Kumar, S., Tamura, K., Jakobsen, I. B. \& Nei, M. (2001). MEGA2: Molecular Evolutionary Genetics Analysis software. Arizona State University, Tempe, AZ, USA. http://www.megasoftware.net

Mandel, M. \& Marmur J. (1968). Use of ultraviolet absorbancetemperature profile for determining the guanine plus cytosine content of DNA. Methods Enzymol 12, 195-206.

Pernodet, J.-L., Boccard, F., Alegre, M.-T., Gagnat, J. \& Guérineau, M. (1989). Organization and nucleotide sequence analysis of a ribosomal RNA gene cluster from Streptomyces ambofaciens. Gene 79, 33-46.

Prauser, H. (1989). Genus Nocardioides Prauser 1976, 61 ${ }^{\mathrm{AL}}$. In Bergey's Manual of Systematic Bacteriology, vol. 4, pp. 2371-2375. Edited by S. T. Williams, M. E. Sharpe \& J. G. Holt. Baltimore: Williams \& Wilkins.
Saitou, N. \& Nei, M. (1987). The neighbor-joining method: a new method for reconstructing phylogenetic trees. Mol Biol Evol 4, 406-425.

Shirling, E. B. \& Gottlieb, D. (1966). Methods for characterization of Streptomyces species. Int J Syst Bacteriol 16, 313-340.

Weisburg, W. G., Barns, S. M., Pelletier, D. A. \& Lane, D. J. (1991). $16 \mathrm{~S}$ ribosomal DNA amplification for phylogenetic study. J Bacteriol 173, 697-703.

Williams, S. T., Goodfellow, M., Alderson, G., Wellington, E. M. H., Sneath, P. H. A. \& Sackin, M. J. (1983). Numerical classification of Streptomyces and related genera. J Gen Microbiol 129, 1743-1813.

Williams, S. T., Goodfellow, M. \& Alderson, G. (1989). Genus Streptomyces Waksman and Henrici 1943, 339 ${ }^{\mathrm{AL}}$. In Bergey's Manual of Systematic Bacteriology, vol. 4, pp. 2452-2492. Edited by S. T. Williams, M. E. Sharpe \& J. G. Holt. Baltimore: Williams \& Wilkins. 